\title{
Comparison of the effects of dexmedetomidine, ketamine, and placebo on emergence agitation after strabismus surgery in children
}

\section{Comparaison des effets de la dexmédétomidine, de la kétamine et d'un placebo sur l'agitation au réveil après une chirurgie du strabisme chez les enfants}

\author{
Jia-Yao Chen, MD $\cdot$ Ji-E. Jia, MD • \\ Ting-Jie Liu, MD • Ming-Ju Qin, MD • \\ Wen-Xian Li, MD \\ Received: 17 June 2012/Accepted: 8 January 2013/Published online: 24 January 2013 \\ (C) Canadian Anesthesiologists' Society 2013
}

\begin{abstract}
Background Children undergoing strabismus surgery under sevoflurane anesthesia often experience emergence agitation (EA) and postoperative vomiting (POV). This study compared the effects of intraoperative dexmedetomidine, ketamine, and placebo on postoperative EA and POV.

Methods Eighty-four children (aged two to seven years) undergoing elective strabismus surgery under sevoflurane anesthesia were randomly assigned to one of three groups $(n=28$ each $)$. Intraoperatively, the placebo, dexmedetomidine, and ketamine groups received normal saline, dexmedetomidine $1 \mu \mathrm{g} \cdot \mathrm{kg}^{-1}$ iv plus a $1 \mu \mathrm{g} \cdot \mathrm{kg}^{-1} \cdot \mathrm{hr}^{-1}$ infusion, and ketamine $1 \mathrm{mg} \cdot \mathrm{kg}^{-1}$ iv plus a $1 \mathrm{mg} \cdot \mathrm{kg}^{-1} \cdot \mathrm{hr}^{-1}$ infusion, respectively. Agitation scores (Pediatric Anesthesia Emergence Delirium [PAED] scale) and POV were assessed in the postanesthetic care unit (PACU) and for 24 $\mathrm{hr}$ on the ward. Pain scores and times to laryngeal mask
\end{abstract}

Jia-Yao Chen and Ji-E. Jia contributed equally to this work.

\section{Author contributions \\ Jia-Yao Chen and Ji-E Jia made substantial contributions to the conception and design of the study, acquisition of data, and analysis and interpretation of data. Jia-Yao Chen, Ting-Jie Liu, and Ming-Ju Qin drafted the article and revised it critically for important intellectual content. Wen-Xian $\mathrm{Li}$ approved the final version to be published.}

J.-Y. Chen, MD · J.-E. Jia, MD · T.-J. Liu, MD ·

M.-J. Qin, MD · W.-X. Li, MD ( $₫)$

Department of Anesthesiology, EENT Hospital,

Shanghai 200031, China

e-mail: wenxianli66@gmail.com airway $\left(L M A^{T M}\right)$ removal, resumption of mental orientation, and discharge from the PACU were also assessed.

Results Seventy-eight children completed the study. Peak $P A E D$ scores for EA were lower in the dexmedetomidine $(P<0.001)$ and ketamine $(P=0.002)$ groups than in the placebo group. Incidence of POV was lower in the dexmedetomidine group (15\%) than in the ketamine $(44 \%$; $P=0.02)$ or placebo (45.8\%; $P=0.02)$ groups. Pain scores on the ward were lower in the dexmedetomidine $(P<0.001)$ and ketamine $(P<0.001)$ groups than in the placebo group. Time to LMA removal was similar in all groups. Time for resumption of mental orientation and time to discharge from PACU were longer in the dexmedetomidine and ketamine groups than in the placebo group.

Conclusions Dexmedetomidine and ketamine appear to prevent postoperative agitation and pain after sevoflurane anesthesia for pediatric strabismus surgery. Dexmedetomidine also prevents $\mathrm{POV}$.

\section{Résumé}

Contexte Les enfants subissant une chirurgie $d u$ strabisme sous anesthésie au sévoflurane manifestent souvent de l'agitation au réveil $(A R)$ et des vomissements postopératoires (VPO). Cette étude a comparé les effets de la dexmédétomidine, de la kétamine et d'un placebo peropératoires sur l'AR et les VPO postopératoires.

Méthode Quatre-vingt-quatre enfants (âgés de deux à sept ans) subissant une chirurgie du strabisme non urgente sous anesthésie au sévoflurane ont été randomisés en trois groupes ( $n=28$ dans chaque groupe). Pendant l'opération, les groupes placebo, dexmédétomidine et kétamine ont reçu du 
sérum physiologique, de la dexmédétomidine $1 \mu \mathrm{g} \cdot \mathrm{kg}^{-1}$ iv plus une perfusion de $1 \mu \mathrm{g} \cdot \mathrm{kg}^{-1} \cdot \mathrm{h}^{-1}$, ou de la kétamine $\mu \mathrm{g} \cdot \mathrm{kg}^{-1}$ iv plus une perfusion de $1 \mu \mathrm{g} \cdot \mathrm{kg}^{-1} \cdot \mathrm{h}^{-1}$, respectivement. Les scores d'agitation (échelle d'agitation au réveil d'une anesthésie pédiatrique [PAED]) et les VPO ont été évalués en salle de réveil et durant 24 hà l'étage. Les scores de douleur et le temps jusqu'au retrait du masque laryngé ( $\left.L M A^{T M}\right)$, le rétablissement de l'orientation mentale et le congé de la salle de réveil ont également été évalués.

Résultats Soixante-dix-huit enfants ont terminé l'étude. Les scores PAED maximaux pour l'AR étaient plus bas dans les groupes dexmédétomidine $(P<0,001)$ et kétamine $(P=0,002)$ que dans le groupe placebo. L'incidence des VPO était plus basse dans le groupe dexmédétomidine (15\%) que dans les groupes kétamine (44\%; P = 0,02) et placebo (45,8\%; $P=0,02)$. Les scores de douleur à l'étage étaient plus bas dans les groupes dexmédétomidine $(P<0,001)$ et kétamine $(P=0,001)$ que dans le groupe placebo. Le temps jusqu'au retrait du masque laryngé était semblable dans tous les groupes. Le temps nécessaire au rétablissement de l'orientation mentale et le temps jusqu'au congé de la salle de réveil étaient plus longs dans les groupes dexmédétomidine et kétamine que dans le groupe placebo.

Conclusion La dexmédétomidine et la kétamine semblent prévenir l'agitation et la douleur postopératoires après une anesthésie au sévoflurane pour la chirurgie pédiatrique du strabisme. La dexmédétomidine prévient également les VPO.

Sevoflurane is frequently used for pediatric anesthesia because it has low pungency and rapid onset and offset of action. $^{1,2}$ The reported incidence of emergence agitation (EA) following sevoflurane anesthesia varies from 10-80\% between studies, ${ }^{3}$ suggesting that EA may depend on numerous factors.

Strabismus surgery is associated with significant postoperative vomiting (POV) and pain, both with incidences of approximately $30 \%$. $^{4,5}$ These symptoms cause obvious postoperative distress for children. The use of opioids for pain management is limited by POV, an important cause of morbidity after strabismus surgery. ${ }^{6}$ Various approaches have been employed to diminish POV, including use of antiemetics; ${ }^{4,7}$ however, the method of choice remains controversial. $^{8}$

Dexmedetomidine, an $\alpha_{2}$-adrenoceptor agonist with sedative, analgesic, and anxiolytic actions, has been used in pediatric and adult populations. ${ }^{9}$ Several prospective clinical trials in children have shown that dexmedetomidine significantly reduces the incidence of EA prior to recovery from sevoflurane anesthesia. ${ }^{10-13}$
Ketamine is an $N$-Methyl-D-aspartate (NMDA) receptor antagonist used clinically as an anesthetic, sedative, and analgesic in pediatric patients undergoing strabismus surgery. It has been reported that ketamine can lower the incidence of postoperative EA, POV, and pain following strabismus surgery when compared with propofol. ${ }^{14}$ There is additional evidence that ketamine decreases the incidence of EA after sevoflurane anesthesia in children undergoing other surgical procedures. ${ }^{15,16}$

Given that both dexmedetomidine and ketamine appear to have beneficial effects in reducing EA and POV in children, the present clinical study was undertaken to investigate the relative benefits of adding dexmedetomidine or ketamine to sevoflurane anesthesia in children undergoing strabismus surgery. The primary objective of this study was to compare the effects of dexmedetomidine, ketamine, and normal saline on the incidence of EA after sevoflurane anesthesia in children. We speculated that the incidence of EA would be lower with dexmedetomidine due to its sedative, anxiolytic, and analgesic effects. The secondary objective was to estimate the effects of the two drugs on POV.

\section{Methods}

Study subjects

The study was approved by the Ethics Review Committee of the Eye, Ear, Nose \& Throat (EENT) Hospital of Fudan University (Shanghai, China). Written informed consent was obtained from the parents or legal guardians of all participants following a detailed description of the purpose and potential benefits of the study. Eighty-four children (two to seven years of age, American Society of Anesthesiologists physical status I-II) undergoing elective strabismus surgery from September 2010 to January 2011 at the Eye, Ear, Nose \& Throat (EENT) Hospital, Shanghai, China were included in the study. None of the included subjects presented with psychiatric disorders, drug allergy, cardiovascular or clotting disorders, or peptic ulcer, and none had a history of previous eye surgery or other surgery, motion sickness, inner ear disorders, or other conditions predisposing to vomiting.

Study treatment and procedures

The subjects were assigned by computer-generated randomization (using the SPSS ${ }^{\circledR}$ statistical software package) to one of three groups, i.e., normal saline (placebo group), dexmedetomidine (dexmedetomidine group), or ketamine 
(ketamine group). The study drugs, prepared by a single physician were isotonic saline solution $50 \mathrm{~mL}$ (placebo group), dexmedetomidine $200 \mu \mathrm{g}$ (Jiangsu Xinchen Pharmaceutical Co., Ltd, Lianyungang, China) dissolved in isotonic saline solution $50 \mathrm{~mL}$ (dexmedetomidine group), or ketamine $200 \mathrm{mg}$ dissolved in isotonic saline solution $50 \mathrm{~mL}$ (ketamine group). The subjects, their family members, and the anesthesiologist were blinded to the study drug.

Prior to the procedure, the patients were fasted for six hours without solid food and for three hours without fluid. Baseline noninvasive blood pressure, heart rate, and oxygen saturation were recorded in the operating room. No pre-anesthetic medication was administered. Anesthesia was induced and maintained with oxygen $\left(\mathrm{F}_{\mathrm{I}} \mathrm{O}_{2}=1.0,5\right.$ $\mathrm{L} \cdot \mathrm{min}^{-1}$ ) and $8 \%$ sevoflurane in all groups. A $22 \mathrm{G}$ cannula was inserted into the dorsal vein of the left hand, and normal saline was infused at a rate of $3 \mathrm{~mL} \cdot \mathrm{kg}^{-1} \cdot \mathrm{hr}^{-1}$ after mask induction. Patients in the placebo, dexmedetomidine, and ketamine groups were administered normal saline $0.25 \mathrm{~mL} \cdot \mathrm{kg}^{-1}$ (placebo), dexmedetomidine $1 \mu \mathrm{g} \cdot \mathrm{kg}^{-1}$, and ketamine $1 \mathrm{mg} \cdot \mathrm{kg}^{-1}$, respectively, each given intravenously over a period of one minute. The respiratory rate, heart rate, noninvasive blood pressure, and peripheral oxygen saturation $\left(\mathrm{SpO}_{2}\right)$ of each patient were monitored by a physician who was blinded to the drug that had been used. Drugs (saline, dexmedetomidine, or ketamine) were infused at a flow rate of $0.25 \mathrm{~mL} \cdot \mathrm{kg}^{-1} \cdot \mathrm{hr}^{-1}$ using an infuser pump. A flexible laryngeal mask airway (flexible $\mathrm{LMA}^{\mathrm{TM}}$ ) (The Laryngeal Mask Company Limited, Singapore) was used for airway maintenance when the children displayed no reaction to scalene muscle stimulation. The sevoflurane concentration (3-4\%), in an oxygen/air mixture that maintained oxygen saturation $>95 \%$ during the surgical procedure, was titrated based on ventilator parameters to maintain end-tidal $\mathrm{CO}_{2}$ partial pressure $\left(\mathrm{P}_{\mathrm{ET}} \mathrm{CO}_{2}\right)$ at $40-45 \mathrm{mmHg}$, with a tidal volume (TV) of $7.0-10 \mathrm{~mL} \cdot \mathrm{kg}^{-1}$, and a respiratory rate (RR) of 20-25 breaths $\min ^{-1}$. Fentanyl $1 \mu \mathrm{g} \cdot \mathrm{kg}^{-1}$ was administered if the patient's heart rate increased by $\geq 20 \%$ during surgery. Since intraoperative use of fentanyl has been shown to reduce the incidence of EA in pediatric patients receiving sevoflurane anesthesia, ${ }^{17}$ subjects receiving fentanyl were excluded from the study; otherwise, this would have introduced a potential source of bias into our analysis.

The minimal heart rate during this procedure was recorded during traction of extraocular muscles. Oculocardiac reflex (OCR) was defined as an acute reduction in heart rate of $\geq 20 \%$ associated with traction on an eye muscle. Atropine $\left(0.01 \mathrm{mg} \cdot \mathrm{kg}^{-1} i \mathrm{v}\right)$ was given in cases where the heart rate did not return to baseline after release of the extraocular muscle or if the reflex recurred. The number of OCR events was recorded.
All patients received topical anesthesia with two conjunctival drops of $0.4 \%$ oxybuprocaine (Laboratoire Chauvin, Aubenas, France) on four occasions: before washing the eye at the beginning of the operation, before incision of the conjunctiva, before closure, and after closure of the conjunctiva. Sevoflurane was turned off and study drugs were discontinued at the end of the surgery. The patients were ventilated with $100 \% \mathrm{O}_{2}$ and transferred to the postanesthesia care unit (PACU). The flexible LMA was removed while the subjects were still under deep anesthesia with $\mathrm{TV} \geq 8 \mathrm{~mL} \cdot \mathrm{kg}^{-1}, \mathrm{RR} \geq 15$ breaths $\cdot \mathrm{min}^{-1}$, and $\mathrm{P}_{\mathrm{ET}} \mathrm{CO}_{2}$ levels of $40-45 \mathrm{mmHg}$. Subjects were discharged from the PACU when they were calm and had an Aldrete score of 9 to 10.

\section{Assessments}

To maintain blinding, the anesthesiologists did not participate in any of the postoperative assessments. Emergence agitation was assessed by a research nurse blinded to patient group assignment using the Pediatric Anesthesia Emergence Delirium (PAED) scale. ${ }^{18}$ The PEAD scale contains five items (eye contact, purposefulness of actions, awareness of surroundings, restlessness and consolability), each scored on a 0 to 4 scale, for a maximum of 20 points. A perfectly calm child scores 0 and extreme agitation corresponds to 20 points. The peak EA score was recorded. Agitation scores $<10$ were interpreted as an absence of agitation, scores $\geq 10$ were regarded as presence of agitation, and scores $\geq 15$ were regarded as severe agitation. ${ }^{19}$ Severely agitated subjects were treated with $1 \mathrm{mg} \cdot \mathrm{kg}^{-1}$ propofol $i v$ at the discretion of the attending anesthesiologist. A second dose of $1 \mathrm{mg} \cdot \mathrm{kg}^{-1}$ propofol iv was given if agitation persisted five minutes after propofol administration with a PAED score $\geq 15$.

The duration of surgery, time from end of surgery to LMA removal, and time from LMA removal to discharge from the PACU were recorded. Time to resumption of mental orientation was defined as the period from discontinuation of anesthetic administration to the time when the subjects could correctly answer one of the following two questions: "Where are you?" and "Who am I?"

Blinded study personnel recorded the number of episodes of vomiting or retching occurring in the PACU and the number of episodes during the $24 \mathrm{hr}$ following return to the ward. For the purpose of the current study, vomiting was defined as the forceful oral expulsion of liquid or solid gastric contents. Both vomiting and retching were considered as vomiting events. Postoperative vomiting was assessed using a numeric rank score, where $0=$ no vomiting, $1=$ vomited once, and $2=$ vomited twice or more. Recurrent vomiting within five minutes was defined as a single episode. Subjects experiencing more than two 
emetic episodes and those requesting an antiemetic were treated with ondansetron $0.1 \mathrm{mg} \cdot \mathrm{kg}^{-1}$. If the vomiting remained uncontrolled, repeat administrations of ondansetron were given up to a maximum total dose of $4 \mathrm{mg}$.

A Children's Hospital of Eastern Ontario Pain Scale (CHEOPS) was used to measure five categories of painrelated behaviour, each scored from 0,1 or 2 , for a maximum score of $10 .^{20}$ The subjects received acetaminophen $20 \mathrm{mg} \cdot \mathrm{kg}^{-1}$ po given every six hours as needed.

\section{Statistical analysis}

The study was powered for two outcomes: PAED score and the incidence of POV. For the present study, a reduction in PAED score of $40 \%$ was defined as clinically significant, and therefore, a sample size of 18 patients in each group was required. Based on a POV incidence of $85 \%$ in strabismus surgery with an estimated reduction in the incidence of emesis of up to $25 \%,{ }^{21} 25$ patients would be required for each group. Twenty-eight patients per group were enrolled to provide for a potential loss of $10 \%$ due to protocol violation.

All statistical analyses were performed with the statistical software $\mathrm{SAS}^{\circledR}$ 9.1.3 (SAS institute, Cary, USA). Parametric data were described as means and standard deviations (SD) and nonparametric data were described as medians and interquartile ranges [IQR]. Intergroup comparisons of age, weight, PAED score, and recovery times were undertaken with Students-Newman-Keuls (SNK), Kruskal-Wallis, and Mann-Whitney tests, as appropriate. Comparisons of the frequencies of vomiting, nausea or retching, and of the frequencies of pain were analyzed using Fisher's exact test. Values of $P<0.05$ were
Table 1 Demographic and clinical data

\begin{tabular}{lclc}
\hline & $\begin{array}{l}\text { Placebo } \\
(n=24)\end{array}$ & $\begin{array}{l}\text { Dexmedetomidine } \\
(n=27)\end{array}$ & $\begin{array}{l}\text { Ketamine } \\
(n=27)\end{array}$ \\
\hline Age (yr), mean (SD) & $4.3(1.1)$ & $4.1(1.3)$ & $4.2(1.2)$ \\
$\begin{array}{l}\text { Weight (kg), mean } \\
\quad(\mathrm{SD})\end{array}$ & $18.0(3.6)$ & $17.3(4.2)$ & $17.7(4.1)$ \\
$\begin{array}{l}\text { Sex (M:F) } \\
\begin{array}{c}\text { Duration of surgery } \\
(\text { min), mean (SD) }\end{array}\end{array}$ & $34.6(7.5)$ & $35.8(7.3)$ & $18: 9$ \\
\hline
\end{tabular}

$\mathrm{SD}=$ standard deviation

considered statistically significant, and a Bonferronicorrected $P$ value of $<0.017$ was required for multiple comparisons.

\section{Results}

Eighty-four subjects were initially enrolled in the study. Six subjects were subsequently excluded from the analysis (four in the placebo group and one in each of the dexmedetomidine and ketamine groups) because of intraoperative administration of fentanyl, and hence, 78 subjects completed the study. The subjects in the three groups were comparable with respect to age, body weight, sex, duration of surgery, and LMA removal time (Table 1). Mean times (standard deviation, SD) for resumption of mental orientation in the dexmedetomidine group [26.8 (5.3) $\mathrm{min}]$ and in the ketamine group [24.5 (4.8) $\mathrm{min}]$ were significantly longer $(P<0.001$ for both) than in the placebo group [15.5 (3.1) min]. Mean times (SD) to discharge from the PACU in the dexmedetomidine [35.4 (4.4) min] and ketamine [33.5

Table 2 Agitation, vomiting, and pain scores

\begin{tabular}{|c|c|c|c|}
\hline & Placebo $(n=24)$ & Dexmedetomidine $(n=27)$ & Ketamine $(n=27)$ \\
\hline Peak PAED score median [IQR] & $9.0[7.8-14.3]$ & $3.5[3.0-6.5]^{*}$ & $4.0[4.5-8.5]^{*}$ \\
\hline PAED score $\geq 10, n(\%)$ & $11 / 24(46 \%)$ & $3 / 27(11 \%)^{*}$ & $6 / 27(22 \%)$ \\
\hline PAED score $\geq 15, n(\%)$ & $6 / 24(25 \%)$ & $1 / 27(4 \%)^{*}$ & $2 / 27(7 \%)$ \\
\hline POV score $(0: 1: 2)$ & $13: 6: 5$ & $23: 3: 1 *^{\dagger}$ & $15: 6: 6$ \\
\hline \multicolumn{4}{|l|}{ Maximum modified CHEOP, median [IQR] } \\
\hline PACU & $2[1-3]$ & $2[1-2]$ & $2[1-2.5]$ \\
\hline On ward & $4[3-5]$ & $2[1-3]^{*}$ & $2[2-3]^{*}$ \\
\hline Oculocardiac reflex requiring atropine, $n(\%)$ & $8(33.3 \%)$ & $1(3.7 \%)^{*}$ & $0(0 \%)^{*}$ \\
\hline LMA removal time (min), mean (SD) & $1.3(0.9)$ & $1.5(1.3)$ & $1.6(0.7)$ \\
\hline Resumption of mental orientation (min), mean (SD) & $15.5(3.1)$ & $26.8(5.3)^{*}$ & $24.5(4.8)^{*}$ \\
\hline Discharge from recovery room (min), mean (SD) & $25.4(3.2)$ & $35.4(4.4)^{*}$ & $33.5(4.4)^{*}$ \\
\hline
\end{tabular}

PAED = Pediatric Anesthesia Emergence Delirium scale (scale 0 to 20); CHEOPS = Children's Hospital of Eastern Ontario Pain Scale (scale 0 to 10); IQR = interquartile range; PACU = postanesthesia care unit; LMA = laryngeal mask airway; POV = postoperative vomiting; $\mathrm{SD}=$ standard deviation. POV scale: $0=$ none, $1=$ one episode of vomiting, $2=$ multiple episodes of vomiting. $* P<0.017$ for dexmedetomidine or ketamine group $v s$ placebo group; ${ }^{\dagger} P<0.017$ for dexmedetomidine $v s$ ketamine group 
(4.4) $\mathrm{min}$ ] groups were also significantly longer $(P<0.001$ for both) than in the placebo group [25.4 (3.2) $\mathrm{min}]$.

As shown in Table 2, the peak PAED scale scores for EA were significantly lower in the dexmedetomidine $(P<0.001)$ and ketamine $(P=0.002)$ groups than in the placebo group. The incidence of agitation (defined as PAED score $\geq 10$ ) was significantly higher in the saline group than in the dexmedetomidine group $(P=0.011)$, and the number of patients who developed severe agitation requiring propofol (PAED score $\geq 15$ ) was also higher in the placebo group than in the dexmedetomidine group $(P=0.042)$. The incidence of agitation and severe agitation in the ketamine group was not significantly different from those in the placebo and dexmedetomidine groups. The incidence of POV within the first $24 \mathrm{hr}$ after surgery was significantly lower in the dexmedetomidine group $(15 \%)$ than in the placebo $(46 \% ; P=0.02)$ or ketamine (44\%; $P=0.02$ ) groups. During the first $24 \mathrm{hr}$ after the operation, severe vomiting requiring administration of antiemetic medication was observed in five subjects in the placebo group, one subject in the dexmedetomidine group, and seven in the ketamine group. Six of these subjects experienced multiple episodes of vomiting. None of the subjects experienced POV while staying in the PACU.

There were no significant between-group differences in the pain scores, measured as maximal CHEOPS in the PACU (Table 2). Nevertheless, pain scores on the ward were significantly lower in the dexmedetomidine and ketamine groups than in the placebo group $(P<0.001$ for both), with no significant difference between the dexmedetomidine and ketamine groups.

No major respiratory adverse effects were reported. The number of intraoperative OCR events was significantly higher in the placebo group $(8 ; 33 \%)$ than in the dexmedetomidine $(1 ; 4 \% ; P=0.006)$ or ketamine $(0 ; 0 \%$; $P=0.001)$ groups. Eight subjects in the placebo group and one subject in the dexmedetomidine group required atropine for persistent bradycardia.

\section{Discussion}

In this study, agitation scores were decreased by the intraoperative administration of either dexmedetomidine or ketamine to children undergoing strabismus surgery under sevoflurane anesthesia. Both drugs were also effective in reducing postoperative pain; however, dexmedetomidine was more effective than ketamine in decreasing the incidence of POV.

Strabismus surgery is performed commonly in children to restore binocular vision and for cosmetic reasons. Undesired effects, including EA, ${ }^{22} \mathrm{POV},{ }^{8}$ and postoperative pain ${ }^{23}$ are a major cause of distress to patients after recovery from general anesthesia. Vomiting can cause disturbance of water and electrolyte balance and hence prolong the stay in hospital. ${ }^{24}$

Early epidemiologic studies reported widely varying incidences of EA in children, ranging from $10-80 \% .^{25,26}$ Although the precise etiology of EA is currently unknown, suggested risk factors include pain, preschool age, the type of otolaryngologic or ophthalmologic procedure performed, and the use of sevoflurane or desflurane. ${ }^{25,26}$ It has been reported that the incidence of POV in children is twice as high as in adults, and age $>3 \mathrm{yr}$ has been proposed as an independent risk factor for POV. ${ }^{27,28}$ In view of these findings, we included children from two to seven years of age in our study.

Increased pain sensation and rapid emergence from anesthesia have been identified as possible causes of EA associated with anesthetic agents such as sevoflurane. ${ }^{29} \mathrm{~A}$ meta-analysis has shown that analgesics alone are unlikely to be associated with a low incidence of EA, and sedation during emergence may also have beneficial effects on EA. ${ }^{3}$ Potentiation of both analgesia and sedation during emergence might therefore be important factors in reducing the incidence of EA following sevoflurane anesthesia.

Dexmedetomidine (an $\alpha_{2}$-adrenoceptor agonist) and ketamine (an NMDA receptor antagonist) are both sedative and hypnotic anesthetic agents. At low doses, dexmedetomidine produces a sedative effect that mimics natural stage 2 non-rapid eye movement sleep; patients remain drowsy but are cooperative and arousable. ${ }^{30}$ Dexmedetomodine has been recently introduced into clinical practice; the optimal clinical dose has not been well documented. Based on experience in previous studies, ${ }^{12,31}$ we selected a $0.7 \mu \mathrm{g} \cdot \mathrm{kg}^{-1}$ dose of dexmedetomidine for our pre-studies of strabismus surgery; however, the level of sedation was not satisfactory for use in ophthalmic surgery, which is itself a risk factor for EA. We therefore selected a higher dose of $1 \mu \mathrm{g} \cdot \mathrm{kg}^{-1}$ to reduce EA and pain scores in the present study.

Ketamine has sedative and amnestic properties and exhibits strong analgesic activity at subanesthetic doses. ${ }^{32}$ In 5-30\% of patients, nightmares and hallucinations occur at high doses of ketamine, but they occur significantly less frequently at doses $<1 \mathrm{mg} \cdot \mathrm{kg}^{-1} \cdot{ }^{33}$ Furthermore, ketamine is not associated with respiratory depression at these lower doses. ${ }^{34}$ None of the subjects in our study developed postoperative hallucinations or nightmares with low-dose ketamine. These findings are in agreement with those of a previous study using the same ketamine dosage regimen in children undergoing strabismus surgery. Other workers have reported a three-fold reduction in the incidence of EA, with no delay in recovery following oral premedication with ketamine $6 \mathrm{mg} \cdot \mathrm{kg}^{-1}$ in children undergoing adenotonsillectomy. ${ }^{34}$ 
In our study, dexmedetomidine $1 \mu \mathrm{g} . \mathrm{kg}^{-1}$ followed by infusion at $1 \mu \mathrm{g} \cdot \mathrm{kg}^{-1} \cdot \mathrm{hr}^{-1}$ was associated with a significant decrease in the incidence of EA relative to the saline control group. The incidence of EA with dexmedetomidine in our study was comparable with that reported by Ibacache et al. ${ }^{11}$

We chose not to include assessment of nausea in our study, as it is difficult to estimate the true incidence of nausea in younger children who may not be able to express their discomfort precisely. We found that the incidence of POV was similar with ketamine and saline, but less with dexmedetomidine. In other studies, dexmedetomidine has been shown to be effective in the treatment of cyclical vomiting. ${ }^{35,36}$ It has also been shown to reduce the requirement for postoperative opioids, thereby lowering the risk of opioid-induced nausea and vomiting. ${ }^{37,38}$ These antiemetic properties of dexmedetomidine further support its use as an adjunct for general anesthesia in children.

Ketamine, as an anesthetic during strabismus surgery, has been reported to reduce the incidences of postoperative EA, POV, and pain when compared with propofol. ${ }^{14}$ In a study by Thorp et al., ${ }^{39}$ a modest increase in vomiting appeared to be associated with high cumulative doses of ketamine $\left(>7 \mathrm{mg} \cdot \mathrm{kg}^{-1}\right)$. In our study, ketamine was neither beneficial nor detrimental on POV, probably because of the low dose used.

The duration of surgery was similar in all three groups. As the surgical procedures were performed by the same surgeon, it is likely that all three groups were subjected to the same degree of painful stimuli. Local anesthetics were administered during the procedure, and none of the subjects exhibited any symptoms of pain in the PACU. The results of the present study are consistent with the hypothesis that postoperative pain was a major factor influencing emergence behaviour in the children enrolled in this trial. Saline was associated with higher postoperative pain scores than use of dexmedetomidine or ketamine. This may be explained by the intrinsic analgesic and sedative properties of dexmedetomidine and ketamine or by an anxiolytic effect of dexmedetomidine not measured by this study. There are sparse clinical data to support the analgesic activity of dexmedetomidine in pediatric populations when used in children who have undergone painful procedures. Nevertheless, the sedative properties of dexmedetomidine during the immediate postoperative period may have contributed to its analgesic effect. ${ }^{31}$

There are a number of limitations to the present study that require consideration when interpreting the results. The study was conducted in children from two to seven years of age, and the incidence of EA in this age group was not completely in agreement with that reported in two to five-year-old preschool children. The number of extraocular muscles that were resected was not recorded, which may have influenced the results, as postoperative pain and possibly EA may increase with the number of muscles involved. In our study, we were unable to account for possible relationships between muscle resection length and the incidence of POV. Further studies are required to address these limitations and verify our findings.

In conclusion, the administration of dexmedetomidine or ketamine to children undergoing strabismus surgery under sevoflurane anesthesia resulted in a reduced incidence of EA and pain compared with placebo. The incidence of POV was significantly lower with dexmedetomidine than with ketamine or placebo. These findings suggest intravenous infusion of dexmedetomidine with sevoflurane may form an effective combination for anesthesia in children undergoing strabismus surgery.

Funding None.

Conflicts of interest None declared.

\section{Appendix}

Consort diagram showing the flow of participants through each stage of the randomized trial. 


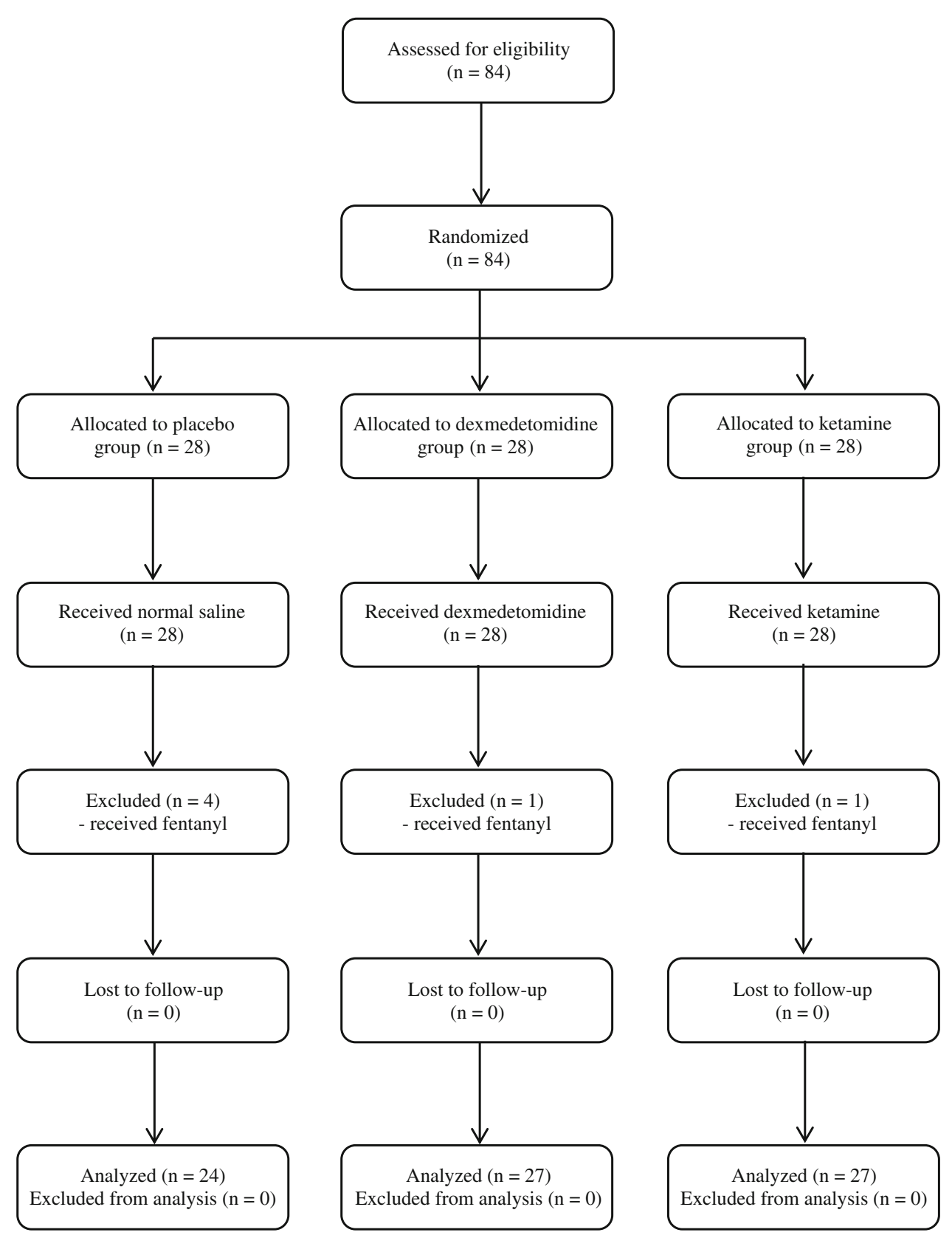

\section{References}

1. Eger EI $2^{\text {nd }}$. Characteristics of anesthetic agents used for induction and maintenance of general anesthesia. Am J Health Syst Pharm 2004; 61(Suppl 4): S3-10.

2. Yamashita $M$. Postanaesthetic excitation and agitation. Paediatr Anaesth 2003; 13: 641; author reply 642-3.

3. Dahmani S, Stany I, Brasher C, et al. Pharmacological prevention of sevoflurane- and desflurane-related emergence agitation in children: a meta-analysis of published studies. Br J Anaesth 2010; 104: 216-23.

4. Chhabra A, Pandey R, Khandelwal M, Subramaniam R, Gupta S. Anesthetic techniques and postoperative emesis in pediatric strabismus surgery. Reg Anesth Pain Med 2005; 30: 43-7.

5. Ecoffey $B$. Recovery and outcome after minor pediatric surgery. Minerva Anestesiol 2002; 68: 392-5.
6. Shende D, Das K. Comparative effects of intravenous ketorolac and pethidine on perioperative analgesia and postoperative nausea and vomiting (PONV) for paediatric strabismus surgery. Acta Anaesthesiol Scand 1999; 43: 265-9.

7. Drake R, Anderson BJ, Persson MA, Thompson JM. Impact of an antiemetic protocol on postoperative nausea and vomiting in children. Paediatr Anaesth 2001; 11: 85-91.

8. Tramer MR. A rational approach to the control of postoperative nausea and vomiting: evidence from systematic reviews. Part I. Efficacy and harm of antiemetic interventions, and methodological issues. Acta Anaesthesiol Scand 2001; 45: 4-13.

9. Su F, Hammer GB. Dexmedetomidine: pediatric pharmacology, clinical uses and safety. Expert Opin Drug Saf 2011; 10: 55-66.

10. Guler G, Akin A, Tosun Z, Ors S, Esmaoglu A, Boyaci A. Singledose dexmedetomidine reduces agitation and provides smooth 
extubation after pediatric adenotonsillectomy. Paediatr Anaesth 2005; 15: 762-6.

11. Ibacache ME, Munoz HR, Brandes V, Morales AL. Single-dose dexmedetomidine reduces agitation after sevoflurane anesthesia in children. Anesth Analg 2004; 98: 60-3.

12. Isik $B$, Arslan $M$, Tunga AD, Kurtipek $O$. Dexmedetomidine decreases emergence agitation in pediatric patients after sevoflurane anesthesia without surgery. Paediatr Anaesth 2006; 16: 748-53.

13. Shukry M, Clyde MC, Kalarickal PL, Ramadhyani U. Does dexmedetomidine prevent emergence delirium in children after sevoflurane-based general anesthesia? Paediatr Anaesth 2005; 15 : 1098-104.

14. Mizrak A, Erbagci I, Arici T, et al. Ketamine versus propofol for strabismus surgery in children. Clin Ophthalmol 2010; 4: 673-9.

15. Abu-Shahwan I, Chowdary K. Ketamine is effective in decreasing the incidence of emergence agitation in children undergoing dental repair under sevoflurane general anesthesia. Paediatr Anaesth 2007; 17: 846-50.

16. Tsai PS, Hsu YW, Lin CS, Ko YP, Huang CJ. Ketamine but not propofol provides additional effects on attenuating sevofluraneinduced emergence agitation in midazolam premedicated pediatric patients. Paediatr Anaesth 2008; 18: 1114-5.

17. Cravero JP, Beach $M$, Thyr B, Whalen $K$. The effect of small dose fentanyl on the emergence characteristics of pediatric patients after sevoflurane anesthesia without surgery. Anesth Analg 2003; 97: 364-7.

18. Sikich N, Lerman J. Development and psychometric evaluation of the pediatric anesthesia emergence delirium scale. Anesthesiology 2004; 100: 1138-45.

19. Bong $C L, N g$ AS. Evaluation of emergence delirium in Asian children using the Pediatric Anesthesia Emergence Delirium Scale. Paediatr Anaesth 2009; 19: 593-600.

20. McGrath PJ, Johnson G, Goodman JT, Schillinger J, Dunn J, Chapman J. CHEOPS: a behavioral scale for rating postoperative pain in children. In: Fields HL, Dubner R, Cervero F, editors. Advances in Pain Research and Therapy, vol. 9. New York: Raven Press; 1985. p. 395-402.

21. Darkow T, Gora-Harper ML, Goulson DT, Record KE. Impact of antiemetic selection on postoperative nausea and vomiting and patient satisfaction. Pharmacotherapy 2001; 21: 540-8.

22. Aouad MT, Nasr VG. Emergence agitation in children: an update. Curr Opin Anaesthesiol 2005; 18: 614-9.

23. Cohen MM, Duncan PG, Pope WD, Wolkenstein C. A survey of 112,000 anaesthetics at one teaching hospital (1975-83). Can Anaesth Soc J 1986; 33: 22-31.
24. Watcha $M F$. The cost-effective management of postoperative nausea and vomiting. Anesthesiology 2000; 92: 931-3.

25. Keaney A, Diviney $D$, Harte $S$, Lyons $B$. Postoperative behavioral changes following anesthesia with sevoflurane. Paediatr Anaesth 2004; 14: 866-70.

26. Voepel-Lewis T, Malviya S, Tait AR. A prospective cohort study of emergence agitation in the pediatric postanesthesia care unit. Anesth Analg 2003; 96: 1625-30.

27. Eberhart LH, Geldner G, Kranke P, et al. The development and validation of a risk score to predict the probability of postoperative vomiting in pediatric patients. Anesth Analg 2004; 99: 1630-7.

28. Kovac AL. Management of postoperative nausea and vomiting in children. Paediatr Drugs 2007; 9: 47-69.

29. Galinkin JL, Fazi LM, Cuy RM, et al. Use of intranasal fentanyl in children undergoing myringotomy and tube placement during halothane and sevoflurane anesthesia. Anesthesiology 2000; 93: 1378-83.

30. Phan H, Nahata MC. Clinical uses of dexmedetomidine in pediatric patients. Paediatr Drugs 2008; 10: 49-69.

31. Yuen VM. Dexmedetomidine: perioperative applications in children. Paediatr Anaesth 2010; 20: 256-64.

32. Warncke T, Stubhaug A, Jorum E. Ketamine, an NMDA receptor antagonist, suppresses spatial and temporal properties of burninduced secondary hyperalgesia in man: a double-blind, crossover comparison with morphine and placebo. Pain 1997; 72: 99-106.

33. White PF, Way WL, Trevor AJ. Ketamine-its pharmacology and therapeutic uses. Anesthesiology 1982; 56: 119-36.

34. Kararmaz A, Kaya S, Turhanoglu S, Ozyilmaz MA. Oral ketamine premedication can prevent emergence agitation in children after desflurane anaesthesia. Paediatr Anaesth 2004; 14: 477-82.

35. Khasawinah TA, Ramirez A, Berkenbosch JW, Tobias JD. Preliminary experience with dexmedetomidine in the treatment of cyclic vomiting syndrome. Am J Ther 2003; 10: 303-7.

36. Tobias JD. Dexmedetomidine in the treatment of cyclic vomiting syndrome. Paediatr Anaesth 2005; 15: 709-10.

37. Gurbet A, Basagan-Mogol E, Turker G, Ugun F, Kaya FN, Ozcan $B$. Intraoperative infusion of dexmedetomidine reduces perioperative analgesic requirements. Can J Anesth 2006; 53: 646-52.

38. Lin TF, Yeh YC, Lin FS, et al. Effect of combining dexmedetomidine and morphine for intravenous patient-controlled analgesia. Br J Anaesth 2009; 102: 117-22.

39. Thorp AW, Brown L, Green SM. Ketamine-associated vomiting: is it dose-related? Pediatr Emerg Care 2009; 25: 15-8. 